\title{
Comparison of an industrial- and a laboratory-scale furnace for analysis of hydrocarbon intumescent coating performance
}

\author{
Zeng, Ying; Erik Weinell, Claus; Dam-Johansen, Kim; Ring, Louise ; Kiil, Søren
}

Published in:

Journal of Fire Sciences

Link to article, DOI:

$10.1177 / 0734904120902852$

Publication date:

2020

Document Version

Peer reviewed version

Link back to DTU Orbit

Citation (APA):

Zeng, Y., Erik Weinell, C., Dam-Johansen, K., Ring, L., \& Kiil, S. (2020). Comparison of an industrial- and a laboratory-scale furnace for analysis of hydrocarbon intumescent coating performance. Journal of Fire Sciences, 38(3), 309-329. https://doi.org/10.1177/0734904120902852

\section{General rights}

Copyright and moral rights for the publications made accessible in the public portal are retained by the authors and/or other copyright owners and it is a condition of accessing publications that users recognise and abide by the legal requirements associated with these rights.

- Users may download and print one copy of any publication from the public portal for the purpose of private study or research.

- You may not further distribute the material or use it for any profit-making activity or commercial gain

- You may freely distribute the URL identifying the publication in the public portal 


\title{
Comparison of an industrial- and a laboratory-scale furnace for analysis of hydrocarbon intumescent coating performance
}

\begin{abstract}
Due to increasing demands for fire protection in high-risk environments, such as petrochemical processes and offshore platforms, so-called hydrocarbon intumescent coatings are increasingly used to protect structural steel in the event of a hydrocarbon fire. For these coatings, the fire-resistance performance is typically evaluated in a series of costly experiments with industrial-scale (i.e. $1-10 \mathrm{~m}^{3}$ ) furnaces, programmed to follow a standard hydrocarbon fire test curve. In the present work, we propose a laboratory-scale furnace for coating evaluation, which can simulate the conditions of a typical hydrocarbon fire curve, i.e. the standard UL1709. In a case study with five hydrocarbon intumescent coating formulations, the correlation between the laboratory- and the industrial-scale furnace was investigated and a good agreement was found for the temperature progression of the coated steel plates. The physical and chemical properties of the intumescent coating chars were also similar for the two furnaces. In summary, the low-cost, time-efficient laboratory-scale furnace can provide reliable screening of hydrocarbon intumescent coatings, and is recommended as a complementary tool for industrial fire tests.
\end{abstract}

Keywords: Structural steel; hydrocarbon intumescent coatings; standard fire-resistance test. 


\section{Introduction}

In the event of a fire in buildings, infrastructure (e.g. airports or skyscrapers) or at onshore or offshore oil rigs, the temperature of unprotected steel constructions may rapidly reach a critical value (around $500{ }^{\circ} \mathrm{C}$ ), where the probability of equipment or building collapse becomes prohibitively high. To avoid such incidents, so-called intumescent coatings can be used as passive fire protection of the steel structures. ${ }^{1}$ Under the influence of heat, an intumescent coating, swells up to 100 times its original thickness and forms a multicellular char layer. ${ }^{1-3}$ The high degree of expansion and the low-density structure make the char layer an insulating barrier that can prolong the time (1-3 h) for safe evacuation of people. ${ }^{4}$

A real fire has a rather complex temperature-time response; it depends on the structure dimensions, the amount and type of combustible materials, and the air available for combustion. ${ }^{5}$ On the other hand, to simulate the evolution of realistic fires and meanwhile, unify the fire test procedures for different experimental facilities and conditions, standard fire test curves with fixed temperature-time responses have been defined. ${ }^{6}$ Depending on the primary "fuel" for the anticipated fire scenario, standard fire test curves are divided into a cellulosic (e.g. ISO 834) and a hydrocarbon (e.g. UL 1709 and BS 476) temperature-time relationship. In Figure 1, three such examples, of which further details can be found elsewhere, ${ }^{1,4}$ are provided. In general, the transient temperature rises of the hydrocarbon curves are much faster than those of the cellulosic type (Figure 1).

The essential parameter of industrial fire tests is the critical temperature at which the structural steel retains only $60 \%$ of its original strength. ${ }^{4}$ For regular loaded components, such as onshore platforms, a temperature of $550{ }^{\circ} \mathrm{C}$ is generally selected as the standard critical temperature, while for heavily loaded components in high-risk environments, such as petrochemical complexes and offshore platforms, a temperature of $400{ }^{\circ} \mathrm{C}$ is normally selected as the standard. ${ }^{4,6} \mathrm{In}$ accordance with the classification of the standard fire test curves, intumescent coatings are grouped into cellulosic- and hydrocarbon intumescent coatings. The former is typically a water- or solvent-based acrylic coating with a dry film thickness of $0.2-5 \mathrm{~mm}$, while a two-component (solvent-free) epoxy system, that permits a film build of $2-40 \mathrm{~mm}$, is particularly suitable for intumescent coatings for hydrocarbon fires. 


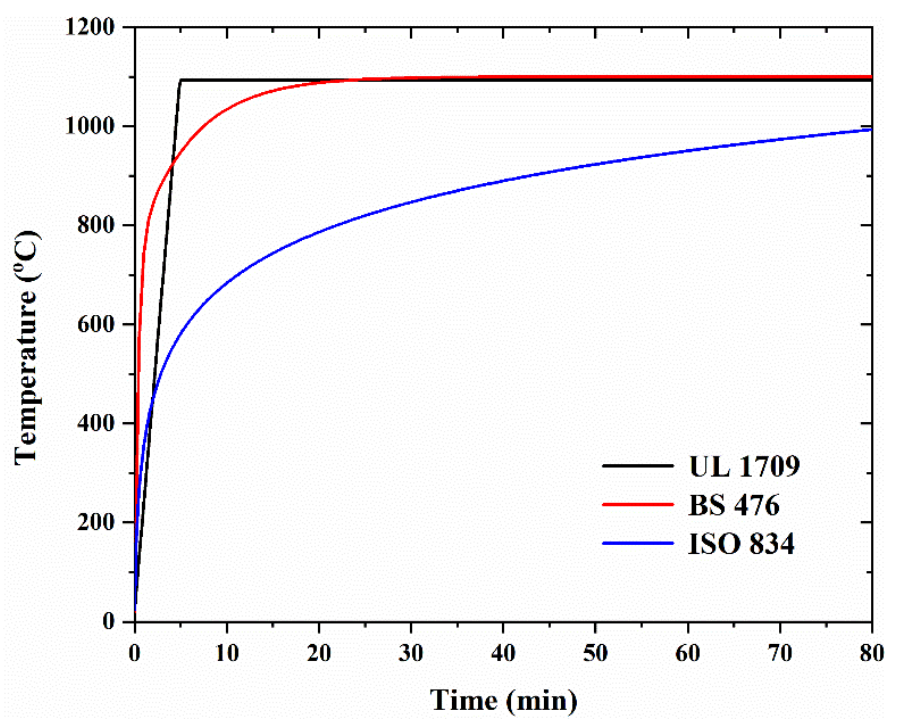

Figure 1 Comparison of the three main standard fire test curves: hydrocarbon type (UL1709, accredited in the US and Canada; BS476, accredited in the UK) and cellulosic type (ISO834).

Industrial fire tests, which are required for third-party approval, are intended to evaluate the ability of an intumescent coating to withstand realistic fire scenarios. However, they are costly to perform and have significant footprints when installed in-house. ${ }^{2,4,7,8}$ Moreover, the coating application is laborintensive (typically four coated steel plates are required for a single experiment) and the testing itself, due to hour-long cooling times of the furnaces, is time-consuming. In addition, the repeatability of the results is often rather poor. ${ }^{2,4}$ As a consequence, accelerated methods are needed for screening of intumescent coatings and for this engineers and scientists use devices like the Bunsen burner, ${ }^{9-11}$ the Gaslamp, ${ }^{12}$ and the cone calorimeter. ${ }^{13-15}$ However, a serious limitation of these devices, due mainly to the limited heating rate (cone calorimeter and radiator) or the unstable/excessive flame temperature (Bunsen burner), is that they cannot meet the requirements of the heating curves defined in the standards (Figure 1). This is a challenge for hydrocarbon intumescent coatings in particular. Moreover, the coated steel plates used in these testing devices often have insufficient or no insulation at all for the sides, allowing heat to dissipate to the surroundings. ${ }^{9-13,16}$ The intumescent coating chars formed under the lower heating rates and temperatures may exhibit incomparable morphological structures and chemical compositions, as well as uncorrelated fire-resistance performance. ${ }^{17-19}$ The design and construction of reliable laboratory-scale furnaces, which can meet the standard fire curves and thereby boost the development of intumescent coatings, such as the rapid screening of formulations and the mapping of the underlying mechanisms, are therefore highly needed.

Several research groups have designed novel testing methods to replace the industrial cellulosic fire tests. ${ }^{2,4,20-22}$ For instance, for simulation of the standard cellulosic test curve ISO 834, a Heat-Transfer 
Rate Inducing System (H-TRIS) was developed by Elliott et al. ${ }^{2,8}$ and Mariappan et al. ${ }^{20}$ developed a bench-scale furnace. However, the hydrocarbon testing curve, which exhibits a high heating rate (more than $200 \mathrm{~K} / \mathrm{min}$ ) to a temperature in excess of $1100{ }^{\circ} \mathrm{C}$, is still a great challenge for laboratory-scale ovens. As an example, the heating curve for the H-TRIS, due to the limited maximum incident heat flux of the radiant heaters in the system, deviates significantly from the desired temperature-time relationship. ${ }^{2}$ Only in the investigations conducted by the group of Bourbigot were it specified that the lab-scale fire-resistance experiments met the requirements of the UL1709 curve. ${ }^{17,21,23-26}$ However, none of these works included validating comparisons with industrial fire tests.

In the present work, a laboratory-scale furnace, which can assess the efficiency of intumescent coatings exposed to a standard hydrocarbon fire curve, is presented. To validate that the furnace allows for a representative approach, fire-resistance experiments (including char expansion) with the setup were carried out and the results, including the physical and chemical properties of the chars formed, were compared to those of an industrial furnace.

\section{Experimental}

\subsection{Coating materials and application}

Five hydrocarbon intumescent coating formulations (F1 - F5) were used in the fire-resistance experiments. The ingredients of the two-component formulations can be found in our previous work ${ }^{27}$ and, for the sake of brevity, the details regarding the compositions are not provided as they are not necessary for discussion. The coating application was initiated by mixing binder and curing agent according to an amide/epoxy functional group stoichiometric ratio of 0.867 . The coating thickness was targeted to $6 \pm 0.2 \mathrm{~mm}$ and the substrate used was a grit-blasted steel plate (area of $60 \times 60 \mathrm{~mm}^{2}$ and 3 $\mathrm{mm}$ thickness for the laboratory-scale fire-resistance experiments; area of 200x300 $\mathrm{mm}^{2}$ and $5 \mathrm{~mm}$ thickness for the industrial fire tests). Plates of $5 \mathrm{~mm}$ thickness are the standard for the industrial fire tests, while the dimension of the steel plates for the laboratory-scale furnace experiments has to be fixed to precisely match with a tailor-cut insulation material (described in the section below). To benefit a long-term investigation with the laboratory-scale furnace and allow comparison with earlier laboratory work (e.g. refs 17,23,28,29), the most common and accessible steel plate thickness, i.e. 3 $\mathrm{mm}$, was selected. No mesh was used to reinforce the coatings. All samples were cured for $24 \mathrm{~h}$ at room temperature before use. 


\subsection{Fire-resistance experiments}

Fire-resistance experiments were performed with a laboratory-scale furnace (in the following referred to as "laboratory-scale fire-resistance experiments") and an industrial-scale furnace (termed "industrial fire tests" in what follows). Although the use of the same hydrocarbon fire curve would be beneficial for a direct comparison, the laboratory-scale fire-resistance experiments and the industrial fire tests were conducted with two different standards (UL1709 and BS476, respectively) due to the limitations of the setups. The industrial furnace was not capable of following the temperature-time profile of UL1709, while the laboratory-scale furnace could not tackle the rapid temperature rise (more than 700 ${ }^{\circ} \mathrm{C} / \mathrm{min}$ ) during the first minute of the BS476 curve. Considering that both standards are industriallyrecognized for evaluating the effects of hydrocarbon fires, it was therefore assumed that the performance of hydrocarbon intumescent coatings is comparable when exposed to the two fire curves.

Such an approach was also used by Jimenez et al., ${ }^{4}$ who disregarded the difference between the targeted curve (UL1709) and the experimental curve (similar to BS476) performed with a gas-fueled benchscale furnace.

\subsubsection{Laboratory-scale furnace}

A compact furnace (LHT 01/17D from Nabertherm $\mathrm{GmbH}$ ), modified with an opening in the furnace door for installation of samples, was used to perform the laboratory-scale fire-resistance experiments. A photo and a schematic diagram of the modified furnace are shown in Figure 2. Prior to an experiment, a coated steel plate is mounted vertically with a tailor-cut insulation material $(50 \mathrm{~mm})$ between the plate backside and the accessories that immobilize the coating and the insulation material in the furnace door opening. This particular arrangement ensures that the sample is well insulated on its unexposed surfaces. The temperature rise of the furnace was measured by a B-type thermocouple (labeled as 2 in Figure 2b) and simulated the temperature-time curve as defined by the UL1709 standard. The temperature-time response of the steel plate was recorded by a copper-disk thermocouple (K-type, 0 $700{ }^{\circ} \mathrm{C}$ ) attached to the central area of the non-coated backside of the steel plate. Once the temperature of the steel plate reached $550{ }^{\circ} \mathrm{C}$, the furnace heating was turned off, the transient experiment thereby covering both of the critical temperatures, 400 and $550{ }^{\circ} \mathrm{C}$. For each of the five hydrocarbon intumescent coating formulations (F1 - F5), a repetition of the laboratory-scale fire-resistance experiment was performed. 
(a)

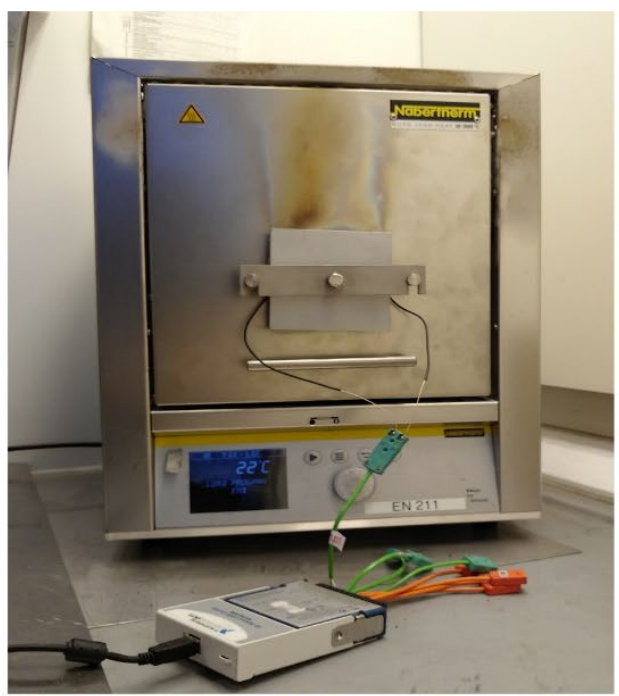

(b)

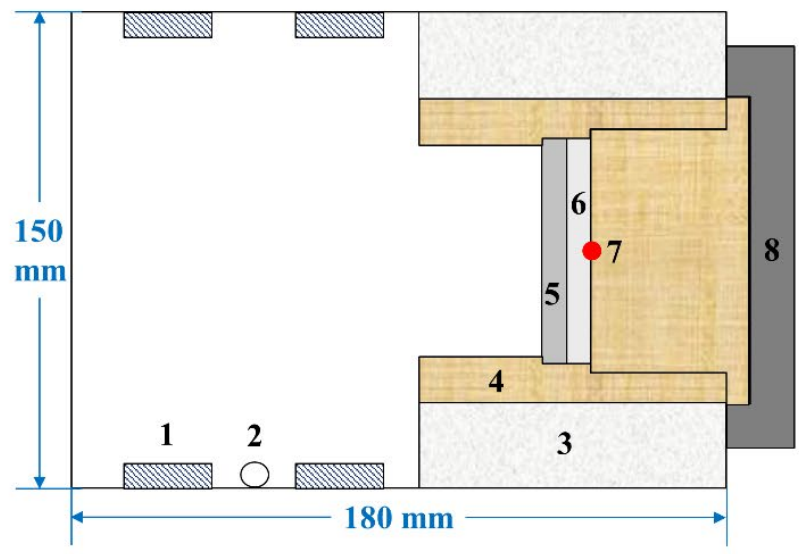

Figure 2 (a) Laboratory-scale furnace for fire-resistance experiments and (b) Schematic diagram of the furnace (seen from above): 1 . heating elements of the furnace; 2 . thermocouple wrapped with ceramic cap (for monitoring the gas temperature of the furnace chamber without influence of radiation); 3. built-in insulation material of the furnace; 4. tailor-cut insulation material (VIP12-HT from Skamol A/S); 5. the intumescent coating; 6. the steel plate; 7. contact point of a copper-disk thermocouple (for measuring the steel temperature); 8. metal accessories for immobilization of samples.

\subsubsection{Industrial fire tests}

Industrial fire tests were performed according to the BS476 hydrocarbon fire standard. The furnace applied has a chamber volume of $7.5 \mathrm{~m}^{3}$ and the furnace door is equipped with four wall penetrations $(200 \times 300 \mathrm{~cm})$ (Figure 3, right). Covering each penetration is a steel plate with intumescent coating, the coating facing the furnace chamber. Two copper-disk thermocouples (K-type, $0-700{ }^{\circ} \mathrm{C}$ ) were attached to the non-coated side of the plate. For insulation of the backside of the steel plate, a fiber blanket (around $5 \mathrm{~cm}$ in thickness) was used, and fixation of a sample in the door was secured with a support panel and tools as shown in Figure 3 (right). Four plates at a time were used for experimentation. The temperature-time response of each plate was the average recorded by the two thermocouples attached (the maximum deviation at any time was less than $30^{\circ} \mathrm{C}$ ). Once the temperature of all four plates reached $550{ }^{\circ} \mathrm{C}$, the furnace was shut down. To evaluate the uncertainties involved, the industrial fire tests of each hydrocarbon intumescent coating were repeated four times. 

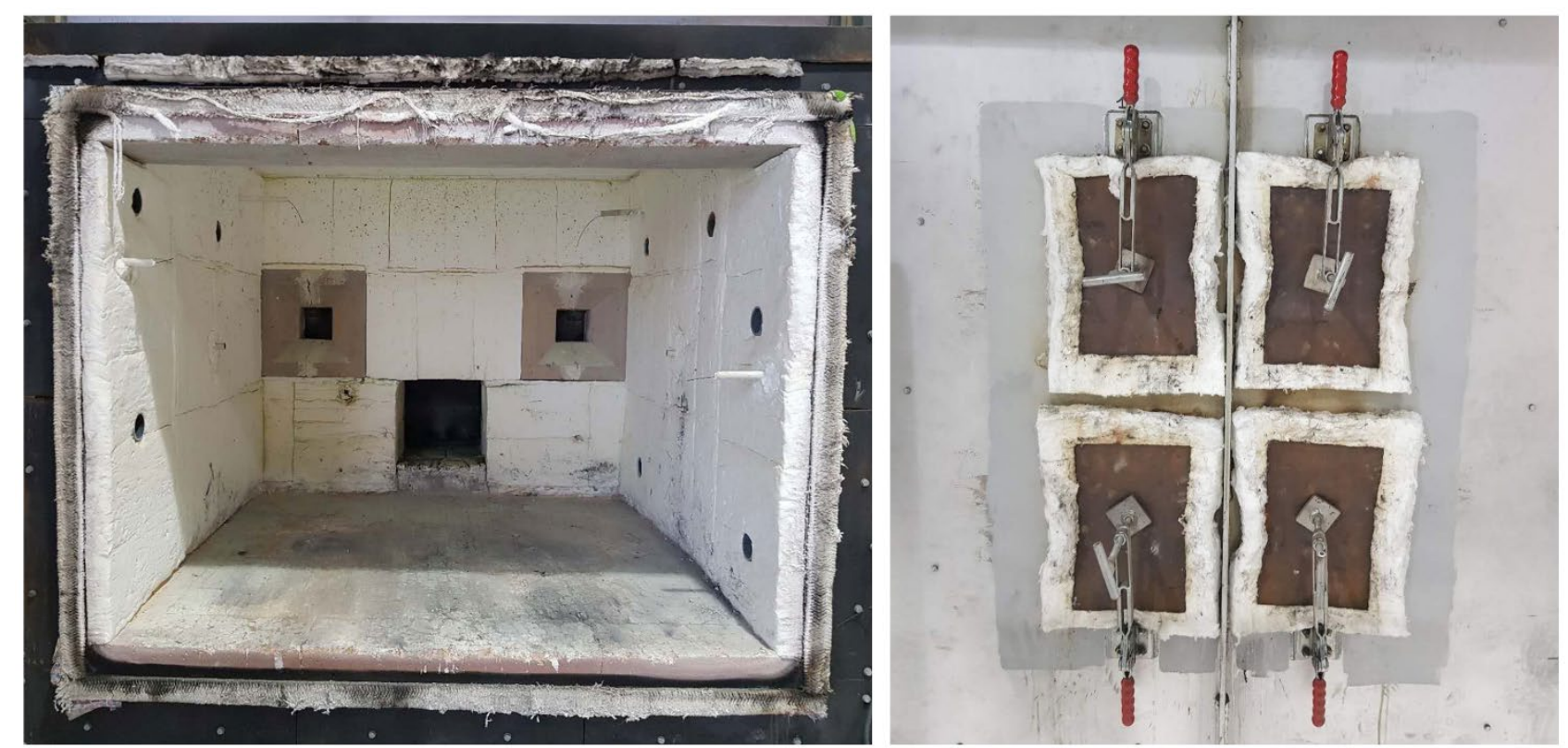

Figure 3 The industrial gas-fired furnace (left) and the outside of the furnace door (right). The steel panels with fixation tools, seen on the right, are not the actual coated steel plates, but merely support panels for the coated steel plates and backside insulation material placed in the door penetrations. The white material framing the support panels is insulation material (fiber blanket).

\subsection{Thermal degradation of hydrocarbon intumescent coatings}

Thermogravimetric analyses of the hydrocarbon intumescent coatings were performed at $213{ }^{\circ} \mathrm{C} / \mathrm{min}$ or $21{ }^{\circ} \mathrm{C} / \mathrm{min}$ in a flow of $\mathrm{N}_{2}\left(79 \mathrm{~mL} / \mathrm{min}\right.$, purity grade 5) and $\mathrm{O}_{2}(21 \mathrm{~mL} / \mathrm{min}$, purity grade 5), using a Netzsch Jupiter F1 STA. The powdery samples (approximately $45 \mathrm{mg}$ ), ground from the free films of the intumescent coatings, were put in alumina crucibles and heated from room temperature to $1000{ }^{\circ} \mathrm{C}$.

\subsection{Identification of crystalline phases of intumescent coating chars with X-ray diffraction}

The crystalline phases of the intumescent coating chars, produced in the laboratory-scale fireresistance experiments and the industrial fire tests, were identified on a Huber G670 powder diffractometer with $\mathrm{Cu}-\mathrm{K} \alpha 1$ radiation $(\lambda=1.54058 \AA, 40 \mathrm{keV}, 40 \mathrm{~mA})$ using a focusing primary monochromator, in transmission mode in the range 3 to $100^{\circ}$ in 2 Theta for 30 minutes.

\subsection{Digital microscope recordings of the intumescent coating char structure}

The intumescent coating chars were cut in half with a scalpel, and the morphological structure of the cross-sections were analyzed with a digital microscope (VHX-6000, from KEYENCE) with a VHZ20T lens, which magnifies up to 200 times. 


\section{Results and discussion}

In the following sections, the experimental results are described and discussed. To address the challenges of developing the laboratory-scale furnace to simulate the standard hydrocarbon fire test curve, the effects of heating rate on intumescent char structures are first considered. Then follows an investigation of the performance of the laboratory-scale furnace and its correlation with the industrial counterpart in terms of assessing fire-resistance properties of hydrocarbon intumescent coatings.

\subsection{Effects of the furnace heating rate on the behavior of hydrocarbon intumescent coatings}

In the literature, laboratory- and industrial-scale furnaces typically employ rather different heating rates. This process parameter is therefore an important point to consider when comparing data from the two scales of operation. However, only in a few studies were the influence of heating rate on the fire-resistance performance and development of the morphological char structure of intumescent coatings considered. Lucherini et al. ${ }^{30,31}$ used the so-called Heat-Transfer Rate Inducing System ( $\mathrm{H}-$ TRIS) test method and found that the onset of swelling of intumescent coatings is directly influenced by the heating conditions at the exposed surface. Nørgaard et al. ${ }^{32}$ found that, unlike the case in regular fire testing, the mechanical resistance of cellulosic intumescent coating chars formed under rapid heating rates (shock heating in a muffle oven), cannot meaningfully be correlated to the degree of char expansion.

As a consequence of these findings, it is essential to consider the effects of heating rate on the behavior of hydrocarbon intumescent coatings, prior to presenting the performance of the laboratory-scale furnace in comparison to the industrial-scale counterpart. For the purpose of demonstration, formulation F3 was selected for the investigation of the possible influences caused by different heating rates. Figure 4 shows the char cross-sections of the coating F3, formed in laboratory-scale furnace experiments using the UL1709 standard (i.e. approximately $210^{\circ} \mathrm{C} / \mathrm{min}$ from ambient temperature to $1093{ }^{\circ} \mathrm{C}$ ) and a non-standard (i.e. $21^{\circ} \mathrm{C} / \mathrm{min}$ from ambient temperature to $1093{ }^{\circ} \mathrm{C}$ ) fire curve, respectively. Here, the heating rate of $21{ }^{\circ} \mathrm{C} / \mathrm{min}$, which is near to the value $\left(2{ }^{\circ} \mathrm{C} / \mathrm{min}\right)$ reported in the literature for examining char expansion and structure, ${ }^{11,16}$ is an example of non-standard heating conditions. The experiments were halted when the temperature of the steel plate reached $350{ }^{\circ} \mathrm{C}$. At this temperature, it is reasonable to assume that the very bottom layer of an intumescent coating has gone into the melting stage (temperature interval of the expansion) and that the intumescent coating has fully expanded. ${ }^{27}$ The chars formed in the laboratory-scale furnace experiments were taken out for observation when the furnace had cooled to room temperature. It can be seen in Figure 4 (and 
repetitions not shown) that compared with the UL1709 curve, the low heating rate conditions give a denser and more lamellar char structure.
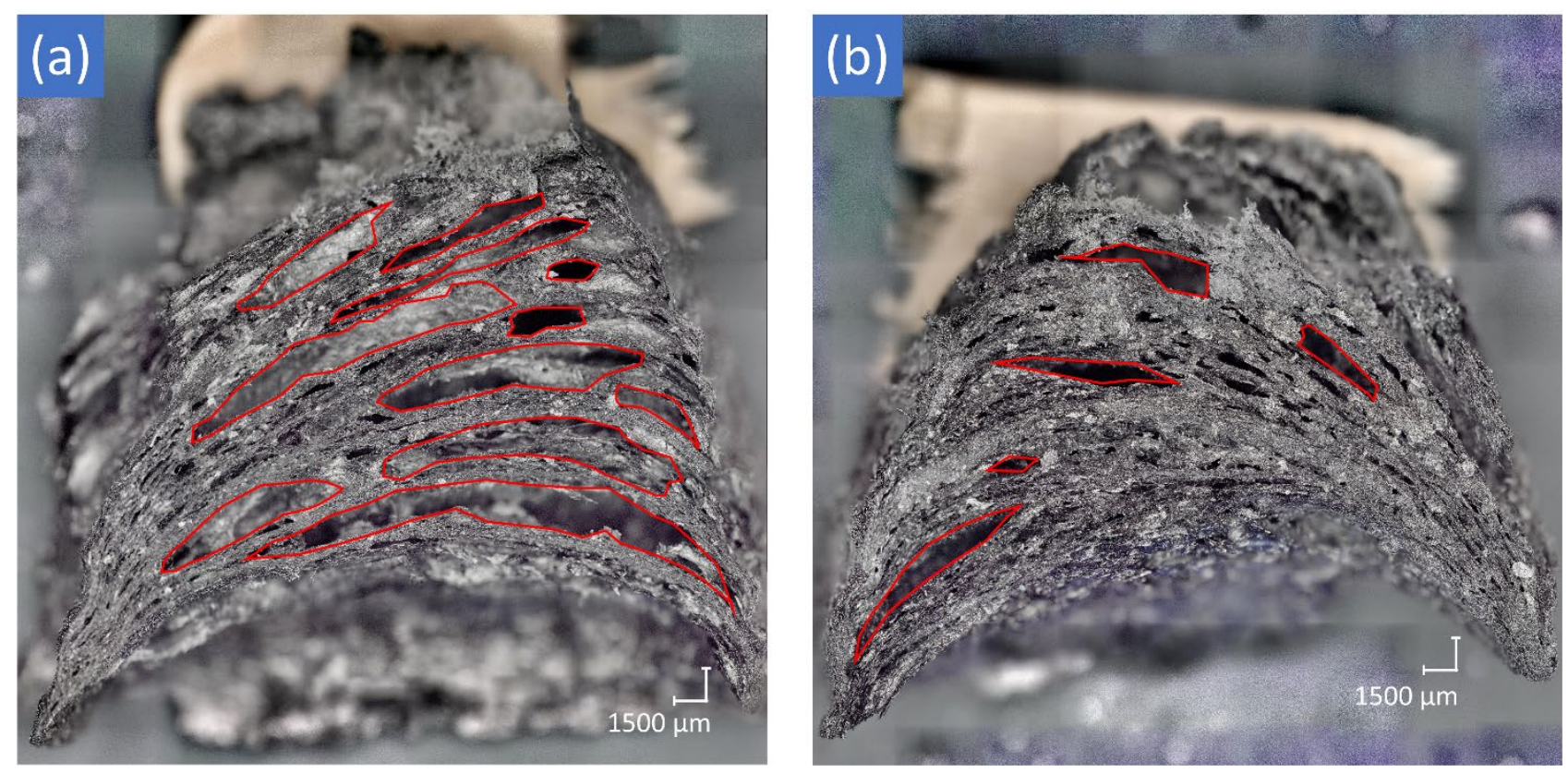

Figure 4 Hydrocarbon intumescent coating chars (formulation F3) formed in a laboratory-scale furnace experiment under different heating conditions: (a) according to the UL1709 curve (i.e. a heating rate of around $210{ }^{\circ} \mathrm{C} / \mathrm{min}$ from ambient temperature to $1093{ }^{\circ} \mathrm{C}$ ), and (b) a heating rate of $21{ }^{\circ} \mathrm{C} / \mathrm{min}$ from ambient temperature to $1093{ }^{\circ} \mathrm{C}$. The significant voids formed, in particular for the conditions underlying the left-hand figure, are emphasized with red markings.

The structure of a fully developed intumescent coating char is mainly a result of the intumescence process, which occurs at temperatures of around 235 to $375{ }^{\circ} \mathrm{C}$, and is characterized by a distinct dynamic viscosity drop of the coating. ${ }^{18,27,33}$ The different interior char structures shown in Figure 4 may, therefore, be explained by the impact of heating rate on the intumescence process. A high heating rate leaves a short time for the intumescence to take place, whereby gases from blowing agents are released at an extreme rate, leading to a structure with big voids (Figure 4). Slower (desired) heating rates may lead to a homogenous structure with small cell volumes.

The heating rate may also influence the thermal decomposition (e.g. gas release of blowing agents) and the chemical composition of an expanding char. Figure 5 shows the chemical degradation of the intumescent coating F3 during the thermogravimetric analyses performed under different heating rates. Even though the residue weights (Figure 5a), at the end of the analyses, are more or less the same, regardless of the different heating rates, the rates of mass loss (Figure 5b) clearly indicate that the thermal degradation steps are strongly related to the heating conditions applied. In particular, the degradation of the coating exposed to the heating rate of $213{ }^{\circ} \mathrm{C} / \mathrm{min}$ occurred mainly before $450{ }^{\circ} \mathrm{C}$ (expeditiously lost $76 \%$ of the total mass loss), while the case using the heating rate of $21{ }^{\circ} \mathrm{C} / \mathrm{min}$ 
degraded more progressively in the whole temperature range of the measurement. It seems plausible that different chemical degradations of an intumescent coating (especially during the intumescence process) can make a difference for the char structure, although the explicit relationship between the degradation and the char structure is not yet known in any details.

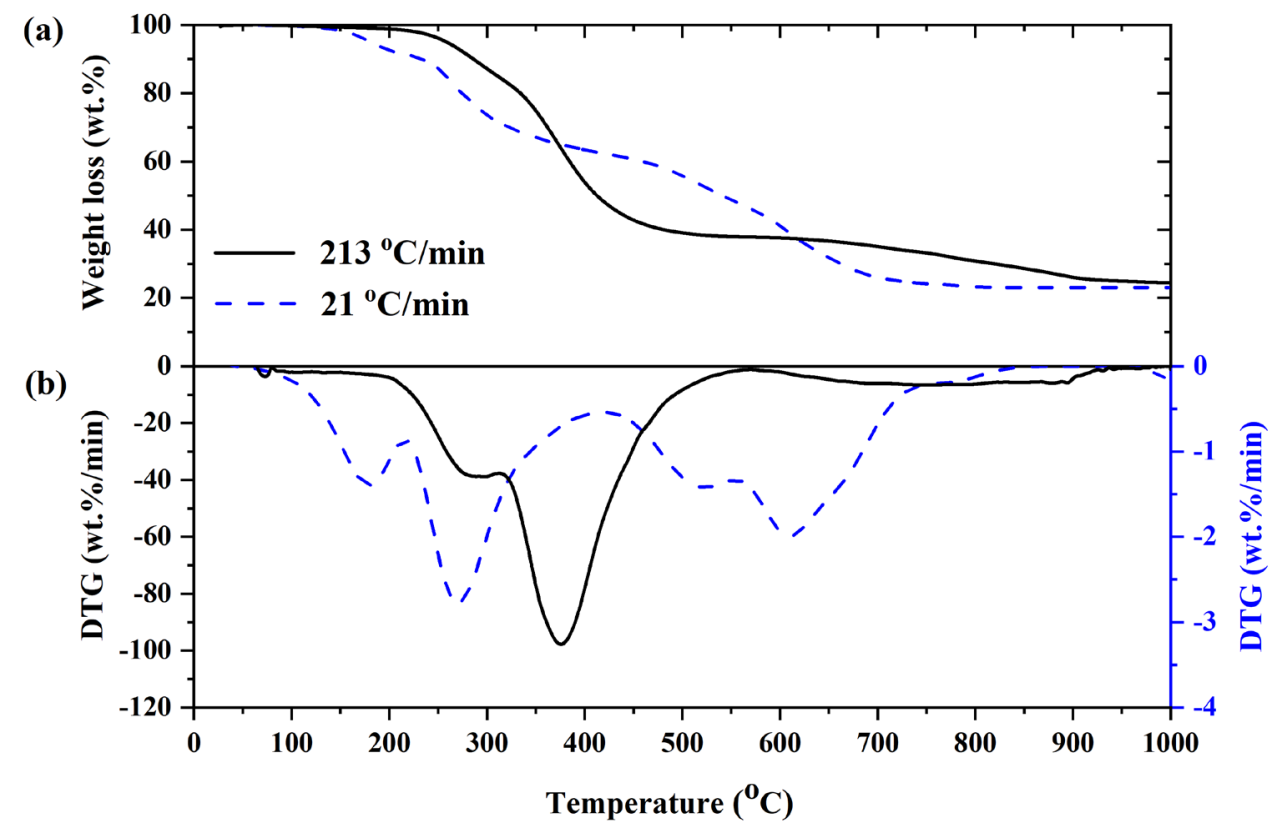

Figure 5 Mass loss curves (a) and the corresponding mass loss rate (b) for the intumescent coating F3 under different heating rates. Note that the two y-axis for the rate of mass loss curves in (b) are different because the time scale for the measurements varied with the heating rate.

In summary, the results demonstrate that the choice of heating rate selected for the fire-resistance evaluation of hydrocarbon intumescent coatings, especially for formulations that form crumbly chars with big cells under a high heating rate (e.g. F3 in Figure 4), is crucial. These fragile char structures are not expected to resist the strong turbulence in a hydrocarbon fire scenario. ${ }^{34-36}$ However, the denser structures formed under too low heating rates may, on the other hand, lead to a wrong assessment of the performance of these coatings.

\subsection{Performance of the laboratory-scale furnace}

For the laboratory-scale furnace to be a reliable tool for evaluation of fire-resistance performance of intumescence coatings, the ability of the furnace to simulate the standard hydrocarbon fire curve and replicate the fire-resistance experiments must be ensured. Figure 6 presents the ability of the laboratory-scale furnace to follow the gas temperature of the UL1709 curve. It can be seen that the experimental curve performed by the laboratory-scale furnace is in very good agreement with the standard (an average temperature of $1093 \pm 56^{\circ} \mathrm{C}$ must be reached within the first $5 \mathrm{~min}^{37}$ ). 


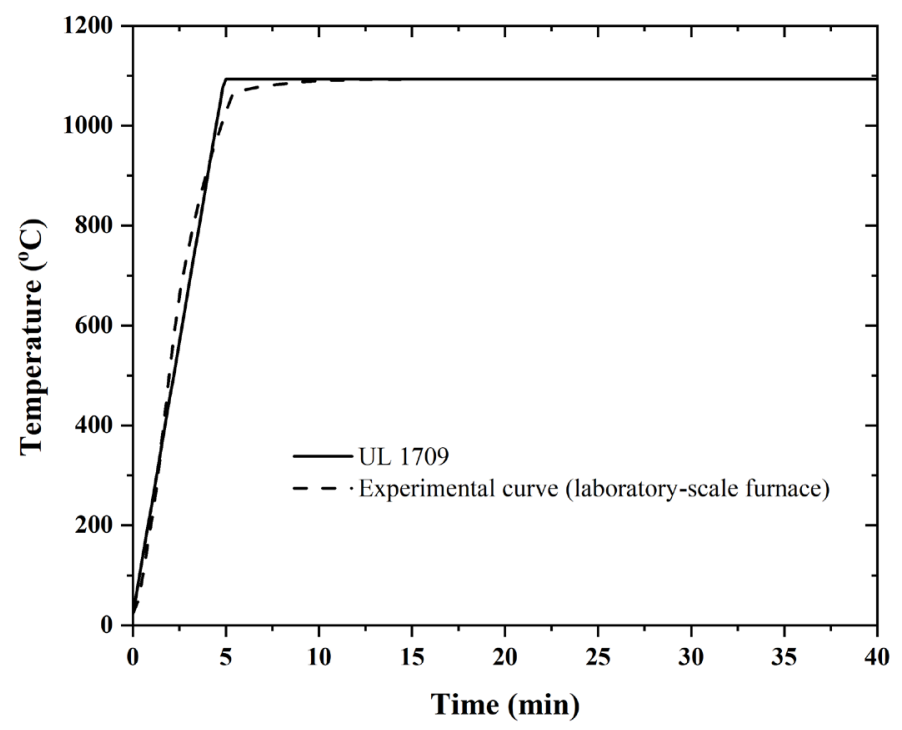

Figure 6 Comparison between the standard and the experimental (laboratory-scale furnace) hydrocarbon curve UL1709.

The repeatability of the furnace was assessed with repetitions of the laboratory-scale fire-resistance experiments with the five hydrocarbon intumescent coatings (F1 - F5). In general, the exposure time of coated steel plates to reach the two critical temperatures $\left(400\right.$ and $\left.550{ }^{\circ} \mathrm{C}\right)$ are repeatable to a relative standard deviation of $3 \%$. Figure 7 shows examples of the temperature-time response for the bare steel plate and the steel plates coated with intumescent coating F1, F3, and F5. The deviation is seen to be negligible, confirming the good repeatability throughout a laboratory-scale fire-resistance experiment.

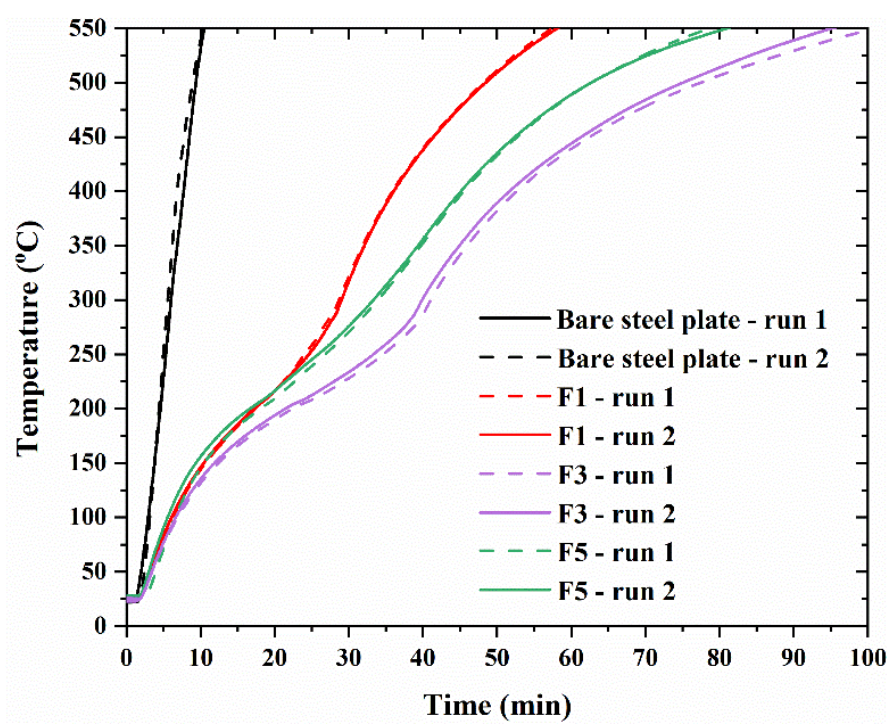

Figure 7 Repeatability runs of the laboratory-scale furnace using a bare steel plate and steel plates coated with intumescent coating F1, F3, and F5. 
3.3. Correlations between coating performance in the laboratory-scale fire-resistance experiments and the industrial fire tests

The potential for using the laboratory-scale furnace for accelerated screening and development work of hydrocarbon intumescent coatings was studied by comparing the two furnace scales with respect to the insulating behavior of the coatings (F1 - F5), as well as the physical and chemical properties of the chars formed in the fire-resistance experiments. In the following paragraphs, the results and correlations obtained are presented and discussed. It is noted that the five intumescent coatings serve as a case study for the potential correlations between the laboratory-scale and the industrial furnace. The mechanisms underlying the different performances of the coatings have not been the focus of the present work and therefore they are not discussed in great detail.

\subsubsection{Fire-resistance performance of intumescent coatings}

The insulating behavior of the hydrocarbon intumescent coatings was examined in fire-resistance experiments with both the laboratory- and industrial-scale furnace. The temperature-time curves of the coated steel plates, each an average of the results from repetitive experiments, are shown in Figure 8. In the case of formulation F3, the measurements from the industrial fire tests showed large uncertainties in the critical times to $550^{\circ} \mathrm{C}$ (the temperature where the fire-resistance experiments were halted), and the average temperature-time response was therefore not available after times longer than $71.6 \mathrm{~min}$ (or temperature higher than $500^{\circ} \mathrm{C}$ ).

A high consistency can be observed in the temperature-time curves of each coating obtained with the laboratory-scale furnace and industrial furnace. All the curves are composed of two arched parts, connected by a transition point at a temperature of approximately $280{ }^{\circ} \mathrm{C}$ (marked with dashed lines in Figure 8). These very similar arched parts suggest that the coated steel plates, in the two setups, generally experienced the same exposure conditions. 


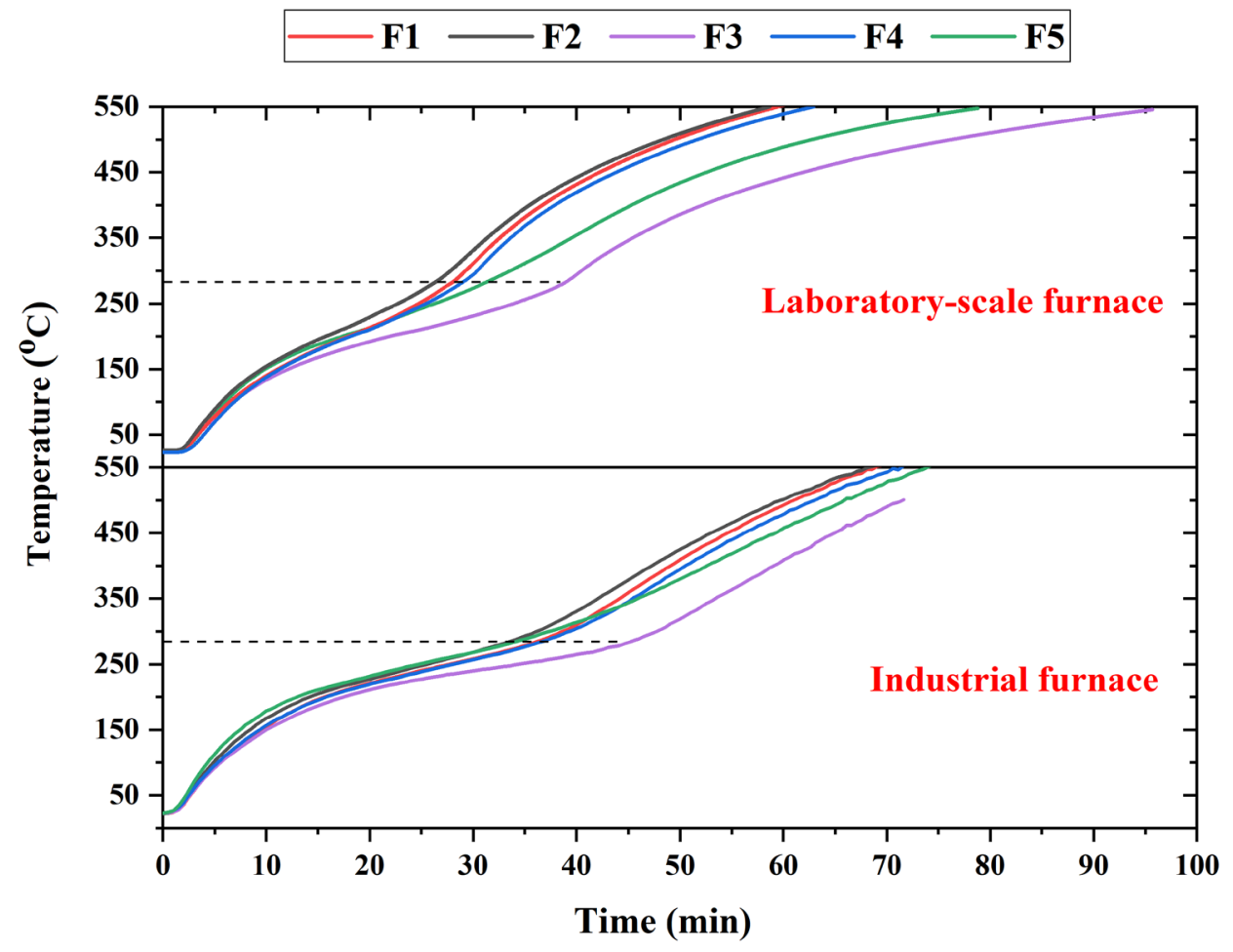

Figure 8 Steel temperature-time curves (industrial and laboratory scale, respectively) for the five coating formulations. The dashed line indicates the approximate transition point of the two arched parts of the curves.

The temperature development is emphasized in Figure 9 where the first derivatives of the temperaturetime curves are plotted with respect to time. For the laboratory-scale furnace experiments, the curves show two distinct peaks. The origin of these peaks can be attributed to the major temperature-related actions of hydrocarbon intumescent coatings: intumescence (from 235 to $375^{\circ} \mathrm{C}$ ) and char degradation (mainly thermal oxidation, from around $540{ }^{\circ} \mathrm{C}$ to the temperature at the end of the experiments). ${ }^{27,33,38-}$ ${ }^{41}$ It is generally acknowledged that the intumescence (i.e. the foaming process) limits the rate of increase of the substrate temperature as a result of the insulating char and the associated endothermic reactions. ${ }^{42}$ Therefore, after a more or less linear temperature rise in the first 5 min (dictated mainly by the flow pattern and the external heat transfer coefficient of the furnace [38]), the intumescence process significantly reduces the heat conduction to the underlying substrate, thereby slowing down the temperate rise of the steel plate.

Due to transition of the char structure from a closed-cell foam to an open-cell sponge induced by carbon loss, thermo-oxidation reactions can decrease the insulating properties of intumescent chars. ${ }^{27,33}$ When the behavior of the intumescent coatings went from intumescence domination to that of thermo-oxidation, the alleviated temperature rise shown in the downhill of the first peak started to increase again (the second peak). At the later stage of the experiments, the main actions of the 
intumescent coatings were completed, yielding a relatively stable carbon-inorganic char. At this point in time, the temperature difference within the system of the steel plate, the residual char, and the furnace chamber $\left(1093{ }^{\circ} \mathrm{C}\right)$ started to decrease, which made the temperature rise of the steel plate descent to a low value.

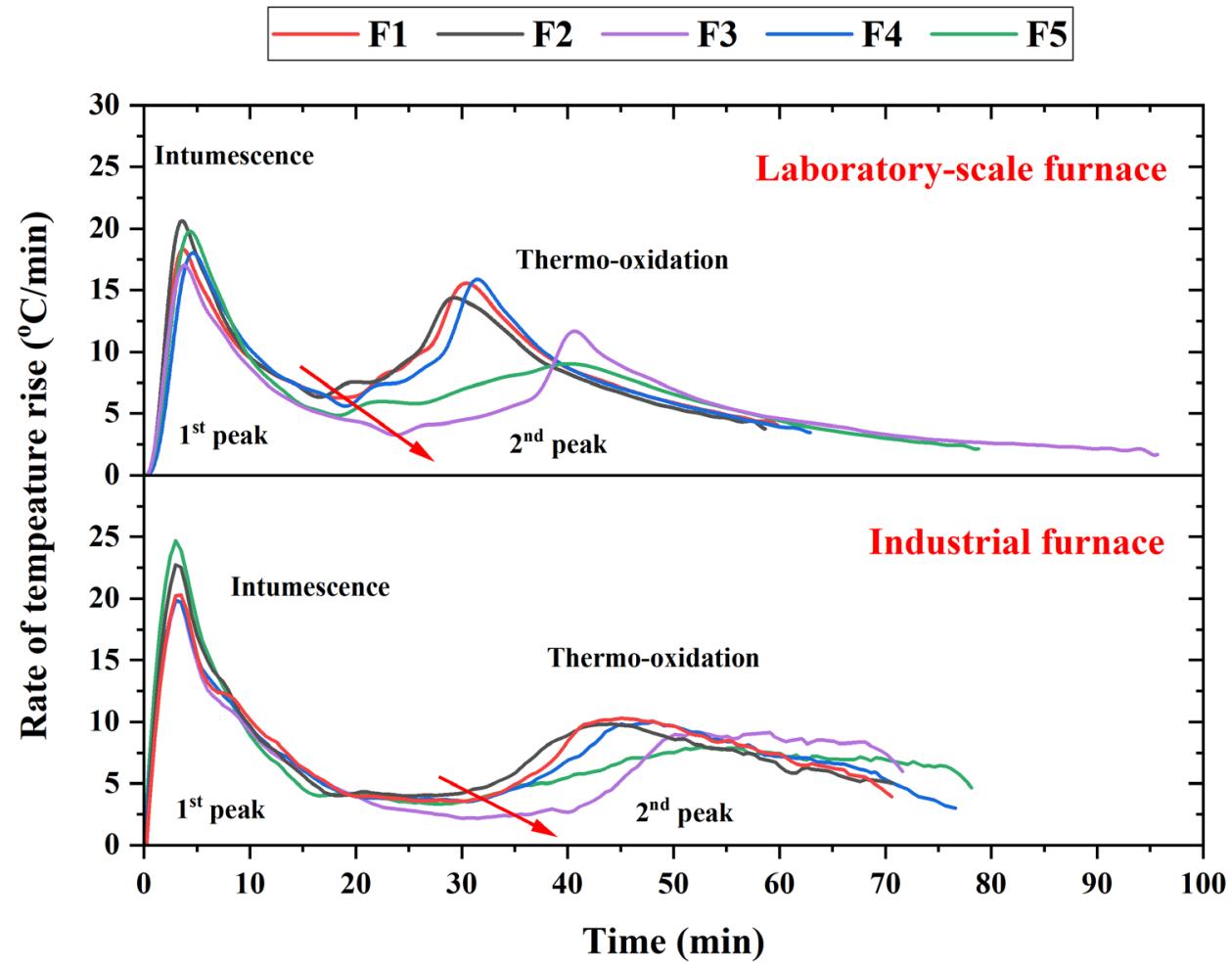

Figure 9 The rate of steel temperature rise (i.e. the first derivative of the temperature-time curve) of coated steel plates with respect to time. The red arrows show the boundary between the first and second peak of each curve.

The results in Figure 9 clearly show that the temperature response of the steel plates in the industrial furnace experiments are driven by the same mode of actions as in the laboratory-scale furnace experiments. The laboratory- and industrial-scale furnace experiments have the boundary between the first and second peak (demonstrated with red solid arrows in Figure 9) at more or less the same temperature $\left(280^{\circ} \mathrm{C}\right)$. This temperature, corresponding to the term of "transition point"' in Figure 8 . The time to the transition point and the maximum of the second peak show the same sequence (ranking) of the coatings in both of the testing methods.

The correlations between the temperature responses obtained with the laboratory- and the industrialscale furnace are emphasized in Figure 10. The dashed line indicates the approximate position of the transition point, which divides the curves into the intumescence and thermo-oxidation region (see Figure 9). An almost linear relationship is evident in the intumescence region, which starts to deviate 
after going into the stage where the thermo-oxidation reactions dominate. At still higher temperatures, the slopes of the curves gradually recover to values comparable to those in the intumescence region.

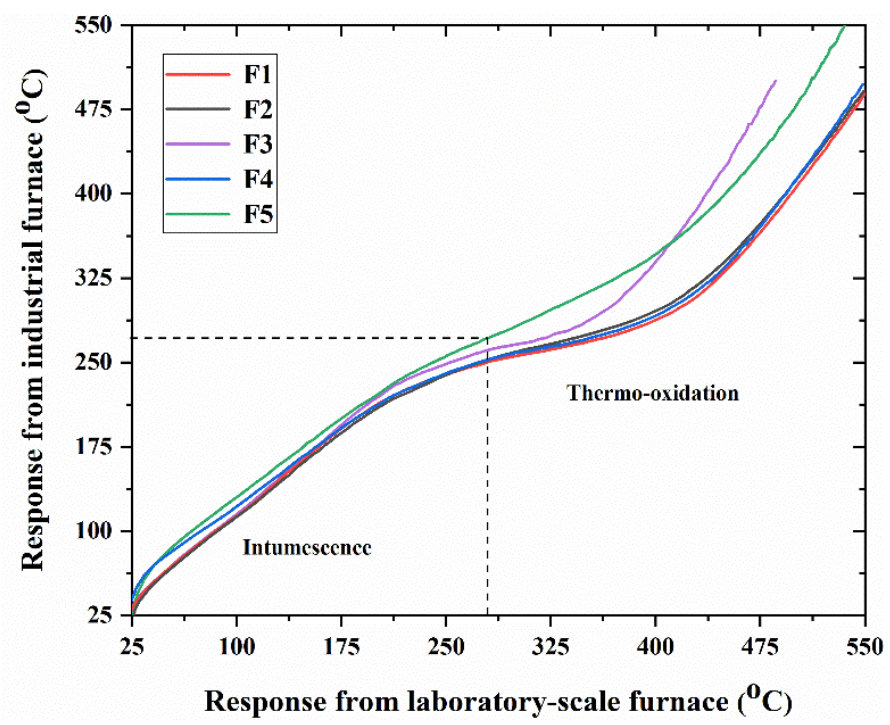

Figure 10 Comparison of temperature responses of the steel plates coated with intumescent coatings obtained in the laboratory- and industrial-scale furnace. The dashed line indicates the transition point defined in Figure 8.

The deviation of the linear relationship observed at the beginning of the thermo-oxidation region, suggests that the thermo-oxidation in the laboratory-scale furnace may be more severe than that taking place in the industrial furnace, resulting in the much faster temperature responses and inclination of the curves towards the $\mathrm{x}$-axis.

Thermo-oxidation of intumescent coatings is affected by oxygen concentration which varies widely in a real fire scenario. ${ }^{41,43}$ In a well-tuned industrial furnace chamber the oxygen concentration is around $4 \mathrm{~mol} \mathrm{\% ,}, 39,41$ while the counterpart in the laboratory-scale furnace chamber was plausibly higher, as the chamber was connected (through the exhaust in the roof of the furnace) to the atmosphere with 21 mol\% of $\mathrm{O}_{2}$. The difference in the oxygen level may account for the different thermo-oxidation conditions in the laboratory- and industrial-scale furnace experiments.

Depending on the anti-oxidation properties of the coating, the more severe oxidation environment in the laboratory-scale furnace would have different impacts on the deviation of the curves. Therefore, as shown in Figure 10, the inclination degree of the curves after the transition point apparently differ for different formulations. Nevertheless, except for the case of F3, the curve progressions are highly consistent with each other and the sequence of the curves is generally constant within the temperature range. The exception observed with F3 for which the curve intersects with the case F5, was caused by surge of the temperature response in the industrial furnace due to detachment of the intumescent char. 
As demonstrated above, the laboratory- and industrial-scale furnace experiments clearly show a strong correlation in terms of the thermal behavior of intumescent coatings and the associated temperature response of the steel plates. This is thought to be due to these two testing methods having similar heating conditions, including heating rate and dwell temperature of the fire curve, and the heat dissipation. Therefore, the performance of the coatings (i.e. the exposure time of the steel plate to critical temperatures) is expected to show a good connection between the laboratory- and industrialscale furnace experiments. The average exposure times to reach the critical temperatures are collected in Figure 11. For each coating, the results from the laboratory- and industrial-scale furnace experiments are comparable. Apart from the cases of formulation F3 and F5 in Figure 11b, the average time to approach the critical temperatures $\left(400\right.$ and $\left.550{ }^{\circ} \mathrm{C}\right)$ in the laboratory-scale furnace experiments is moderately shorter than that in the industrial furnace. It is, as explained above, mainly related to the more severe thermo-oxidation conditions which speed up the temperature rise of the steel plates in the laboratory-scale furnace. The exceptions in the formulations F3 and F5 are related to char defects (e.g. detachments and/or cracks) formed in the industrial furnace and discussed in the next section. The most important observation in Figure 11 is that the intumescent coatings show the same ranking of exposure time to reach the critical temperatures in the laboratory-scale and industrial furnace experiments:

$$
F 3>F 5>F 4>F 1>F 2
$$

Moreover, compared with the industrial furnace, a better repeatability with negligible standard deviation is seen in the results from the laboratory-scale setup. These results indicate that the laboratory-scale furnace can be an effective device to ranking of the fire-resistance performance of hydrocarbon intumescent coatings, and for studies of the underlying mechanisms. 

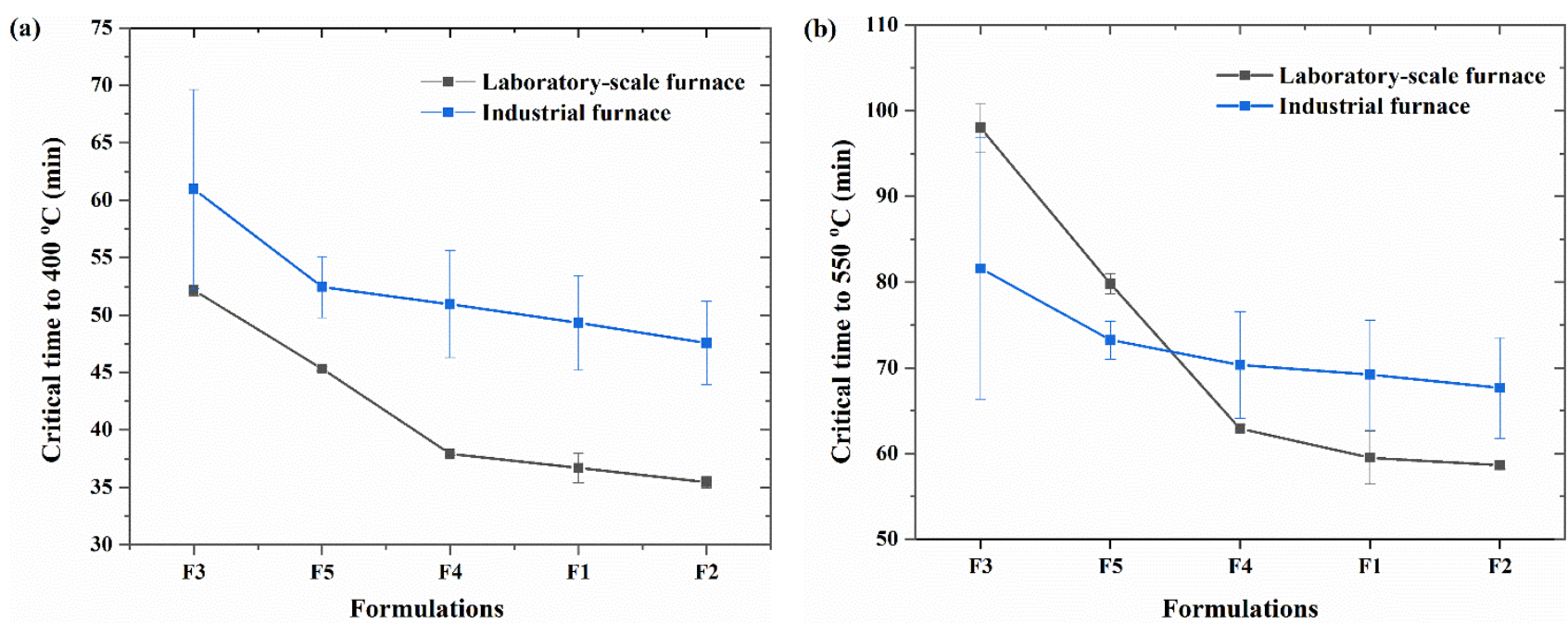

Figure 11 Average exposure times for the coated steel substrate to reach (a) $400{ }^{\circ} \mathrm{C}$ and (b) $550{ }^{\circ} \mathrm{C}$. Error bars correspond to the standard deviation of repetitive furnace experiments.

\subsubsection{Physical appearance of intumescent chars}

The intumescent chars from the furnace experiments were taken out for analyses once the furnace was cooled to room temperature. The aim was to study the interrelationship between the chars formed in the laboratory- and industrial-scale furnace experiments. The relative expansion of the intumescent coatings (i.e. the average height of an intumescent char relative to its initial coating thickness) was first examined, because char thickness is usually one of the most crucial parameters for good protection performance. ${ }^{33}$ The results for the relative expansion of the coatings are presented in Figure 12 with error bars given by standard deviation of the repetitive experiments. 


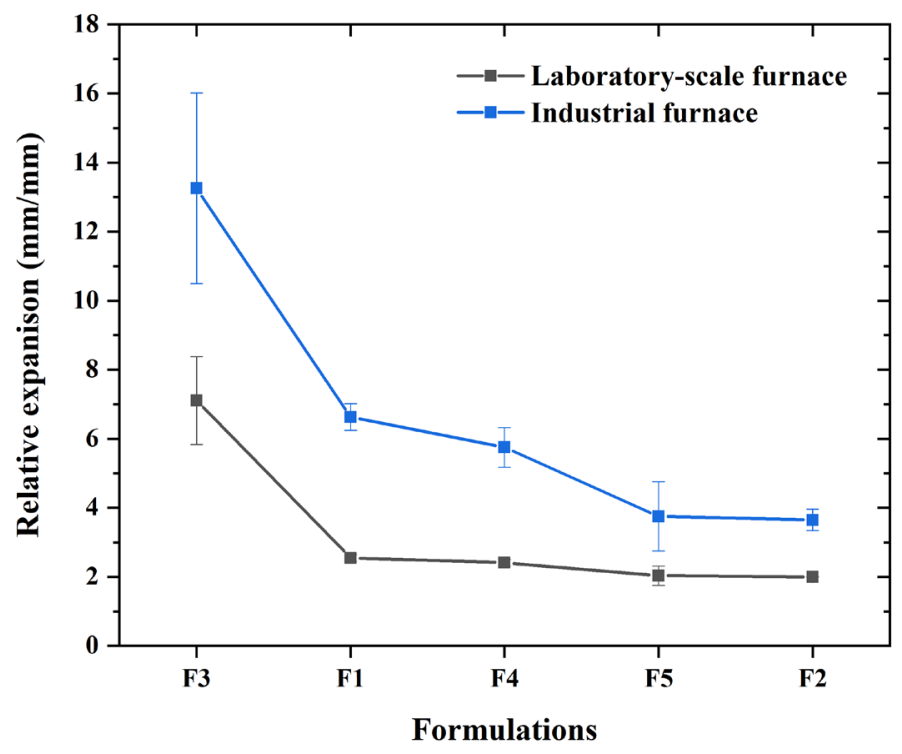

Figure 12 Char expansions after furnace experiments, relative to the initial coating thickness. Error bars represent the standard deviations.

It can be seen that the expansion of the coatings in the laboratory-scale furnace experiments is less than those of the industrial furnace. The limited expansion is probably related to the edge effects introduced by the reduced sample size in the laboratory-scale furnace experiments. For a given coating sample, the edges were protected by the use of insulation materials during the furnace experiments (e.g. see schematic diagram of the laboratory-scale furnace in Figure 2). This .configuration gives an arc-shaped intumescent char for which the expansion close to the edge can be seen to be somewhat restricted. The restricted area apparently constitutes a higher proportion for the samples with a reduced size. The difference in char expansion among the coatings evaluated with the laboratory-scale furnace (except for formulation F3) is quite small as shown in Figure 12. However, the sequence of the relative expansions in the case of the laboratory-scale furnace, follows the same order as that of in the industrial furnace experiments:

$$
F 3>F 1>F 4>F 5 \approx F 2
$$

The agreement in the relative expansion is another important advantage of the laboratory-scale furnace for assessment and development of hydrocarbon intumescent coatings, aside from the fire-resistance ranking described above. Nevertheless, it should be noted that many recent studies have pointed out the limitation of char thickness in predicting the performance of intumescent coatings, especially in the circumstance of hydrocarbon intumescent coatings. ${ }^{27,33}$ Mechanical stability and thermal antioxidation of intumescent chars are increasingly emphasized as means to resist the high temperature and violent thermal shock of hydrocarbon fire scenarios. Figure 13 shows the cross-sections of the 
intumescent chars from the laboratory- and industrial-scale furnace experiments. No distinct differences were found between formulations F1 and F4 with respect to the cross-sectional structure (and also the relative expansion if the deviations in Figure 12 are taken into account). Therefore, the cross-section of F4 is taken as being representative. For better observation and comparison, the magnified images of the cross-sections were recorded with a digital microscope and the results are shown in Figure 14.

\section{(a) Industrial furnace}
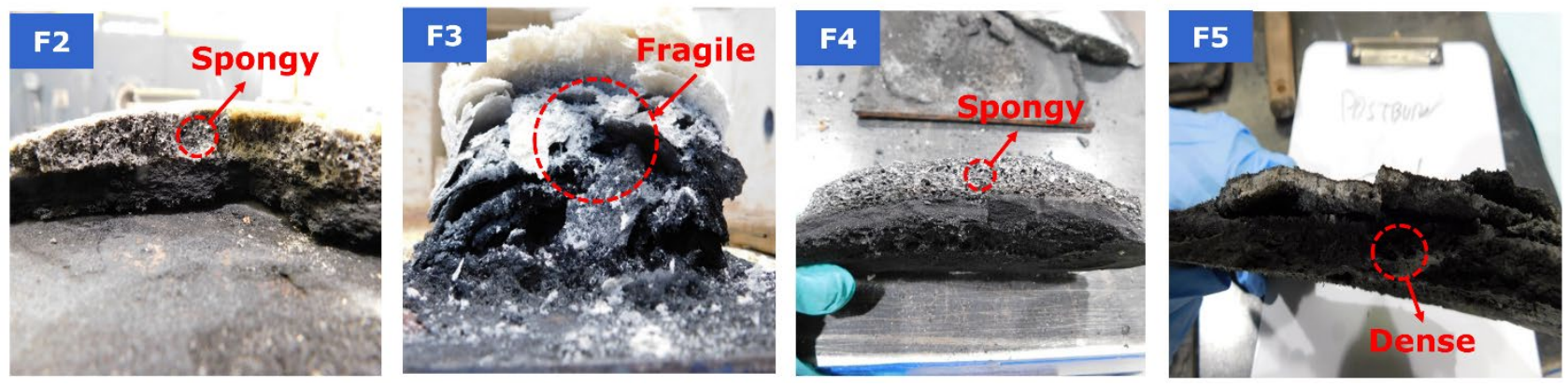

\section{(b) Laboratory-scale furnace}
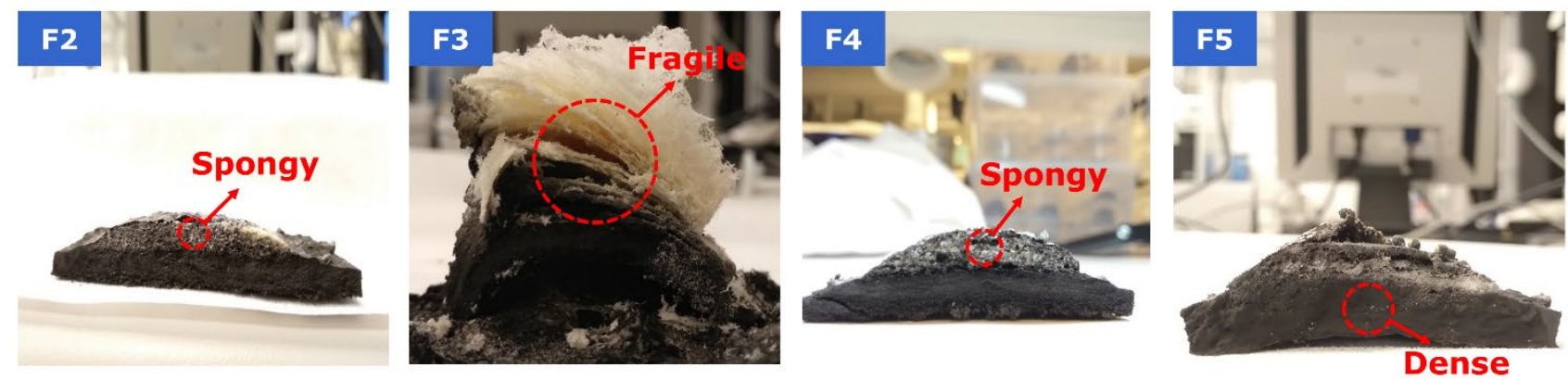

Figure 13 The cross-sections of the intumescent coating chars (after use of a scalpel) formed in the industrial (a) and the laboratory-scale (b) furnace. For reasons of space, a photo of the F1 char is not shown (it looked very similar to the F4 char). 


\section{(a) Industrial furnace}
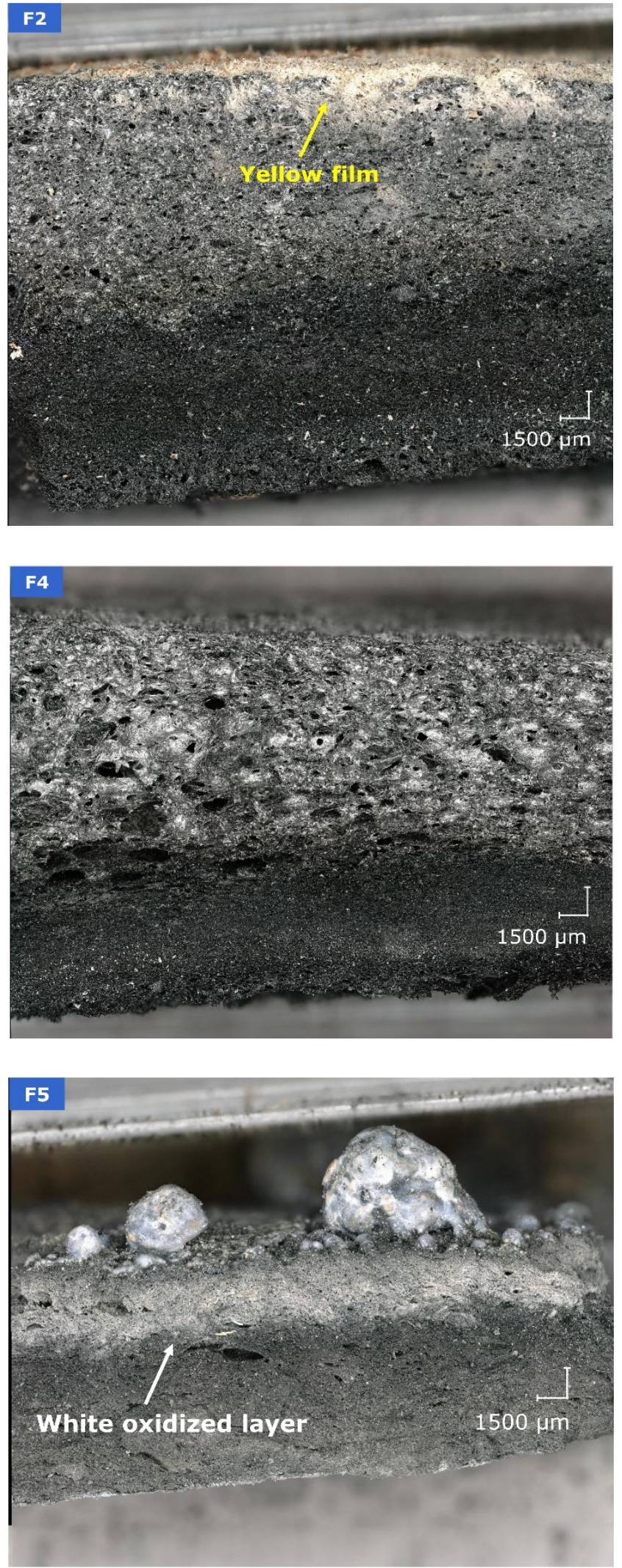

(b) Laboratory-scale furnace

F2

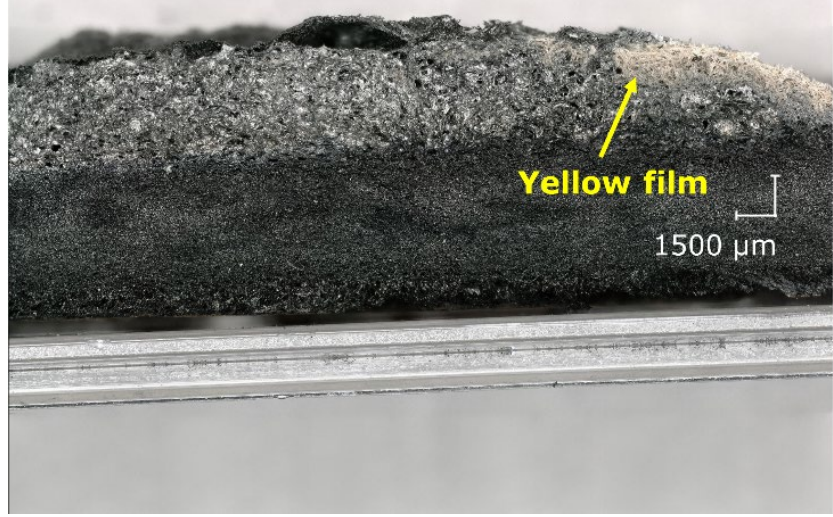

F4

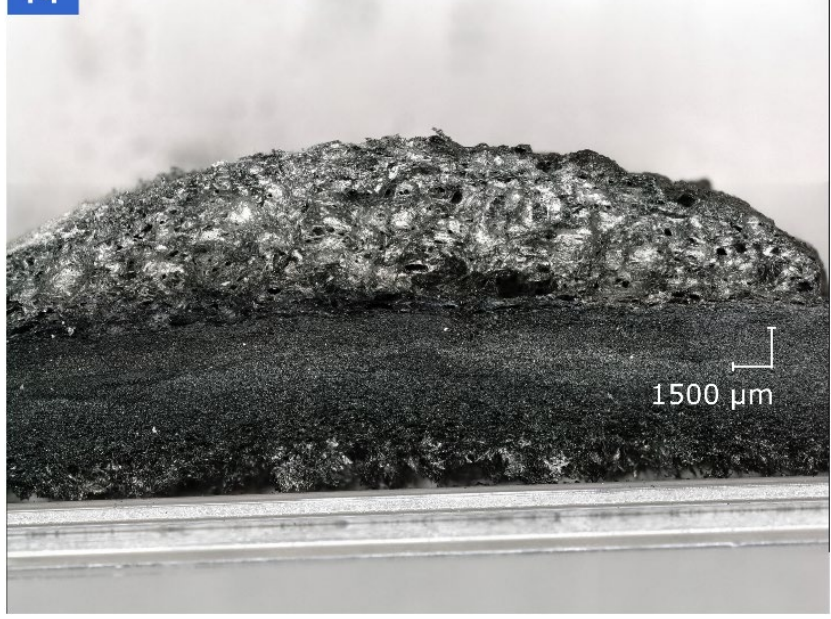

F5

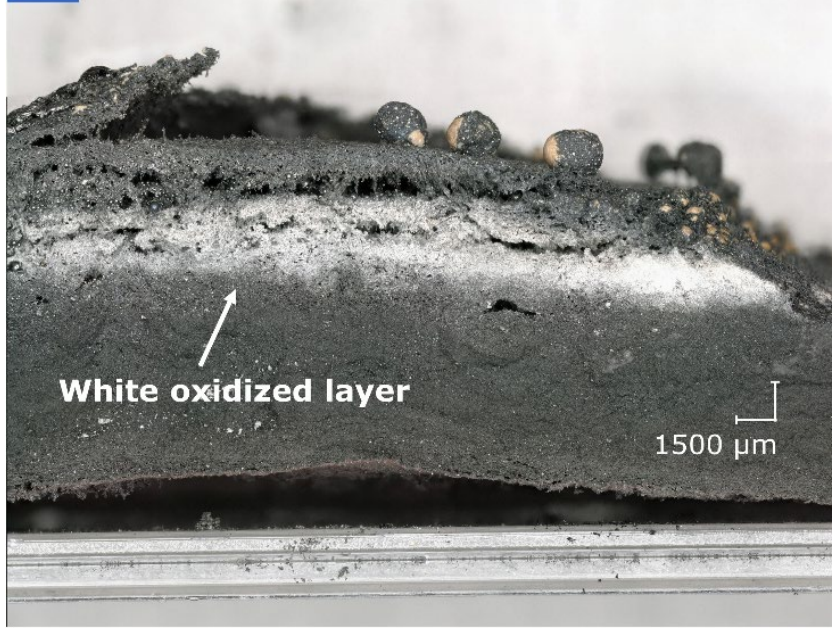

Figure 14 The structures of the char cross-sections magnified by a digital microscope ( $30 \mathrm{x}$ magnification). The intumescent char F3 was very fragile and crumbly and could not be placed on the stage of the digital microscope without falling apart. 
The cross-sections in the cases of the industrial furnace experiments (Figure 13a and 14a) show different characteristics depending on the varying formulations. A two-layered structure is observed in the chars from formulation F2 and F4. The top layer has a sponge-like light grey appearance, and the bottom is a bulk of black dense char. The main difference between the chars F2 and F4 is in their top layers. Compared with char F4, char F2 exhibits smaller cell size in the spongy structure and a particular yellow film on the char surface which is probably the result of severe oxidation. The Formulation F3 gave a fragile and fluffy char, which is challenging to maintain while performing the cross-sectional cutting and microscope recordings. The magnified image of char F3 is therefore not shown in Figure 14 because it fell apart. On the contrary, a tough and dense char with delaminated shell and white oxidized layer on the top was obtained with formulation F5. The tricky structures from formulation F3 (crumpled ashes) and F5 (cracks and delamination) bring large deviations in determining the relative expansion of the coatings, as seen in Figure 12.

The images in Figure 13b and Figure 14b clearly show that the chars formed in the laboratory-scale furnace experiments are rather similar to those developed in the industrial tests. One difference is that the structural defects (detachment and cracks) are more severe in the industrial furnace experiments due to its strong turbulent flow from gas combustion. The structural defects, especially the detachments, can significantly speed up the temperature rise of coated steel plates, which may explain the exceptions mentioned earlier in Figure 11b; the coatings F3 and F5, when exposed in the industrial furnace, exhibits a shorter time to $550{ }^{\circ} \mathrm{C}$ than in the laboratory-scale furnace. Nevertheless, the similarity in the relative expansion and morphological structure suggests that hydrocarbon intumescent coatings assessed in the laboratory-scale furnace can provide valuable information on the physical properties of the chars, comparable to those observed in the industrial furnace tests.

\subsubsection{Crystalline phases in the intumescent char layers}

Apart from the physical appearance, the chemical compositions of the chars were examined to comprehensively establish the correlations between the chars formed in the laboratory- and industrialscale furnaces. The chars were divided into three zones (layers), based on color and structure, as described elsewhere. ${ }^{27}$ The crystalline phases in each layer were analyzed using X-ray diffraction (XRD) and the results are presented in Figure 15. The comparison in terms of formulation F1 was excluded due to its resemblance to F4 in fire-resistance performance and physical appearance of char. The objective here is to compare the diffraction patterns of the chars produced in the two furnaces, rather than to investigate the details of the crystalline phases in a sample. Therefore, instead of 
identifying all the peaks in the X-ray diffraction patterns, only the main crystalline phases are marked out.

Figure 15 shows that the diffraction patterns vary with the different formulations and layers of a char. Titanium phosphate and titanium dioxide (rutile crystal form) are the main phases in all the chars, while the diffraction signals of boron phosphate present in particular in the patterns of the char F4 and F5. The diffraction intensity of these main phases and other unidentified peaks varies with the depth of a specific char. This makes sense because thermal degradation of intumescent coatings is a continuous process which moves from the coating surface toward the layer just above a steel plate. Different layers of a char are at different stages of degradation, which therefore results in distinct chemical compositions.

When focusing on a specific formulation and a "layer", for instance, the top layer of char F2, it can be seen that the patterns barely diverge, regardless of the furnace used for the experiments. The high affinity of the patterns implies that the chars produced from the laboratory- and industrial-scale furnace share not only the identifiable crystalline phases but also the non-recognized amorphous signals. A strong correlation is therefore demonstrated between the chemical compositions of the chars formed in the two furnaces.

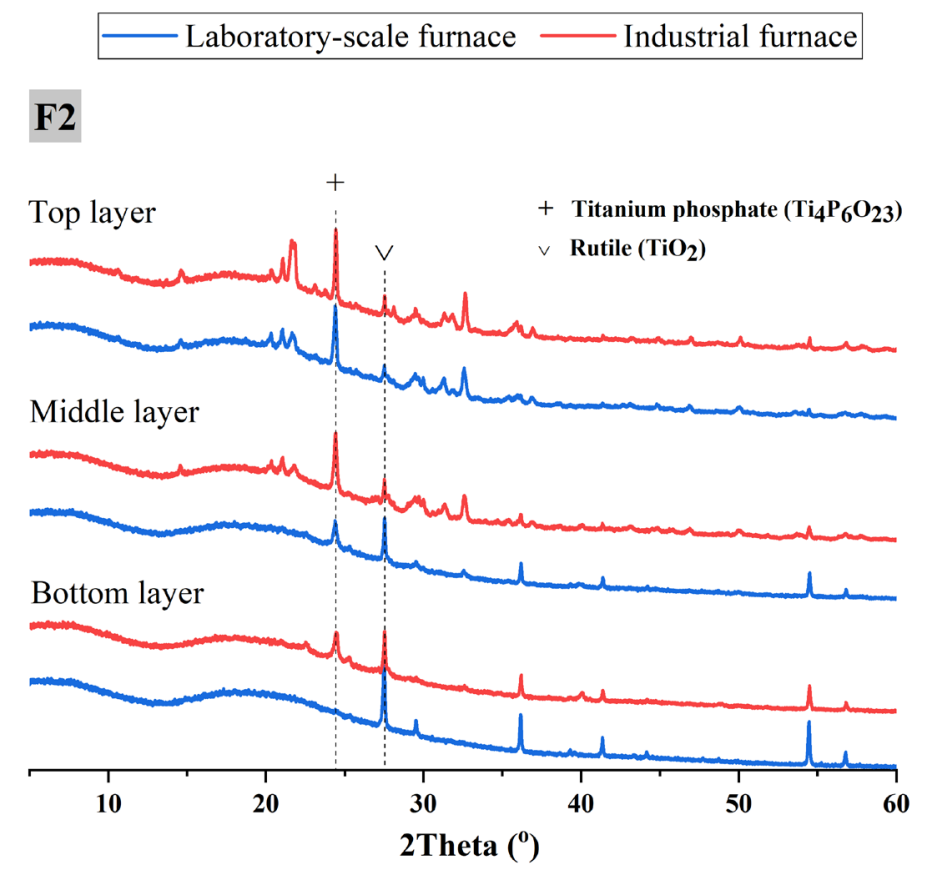




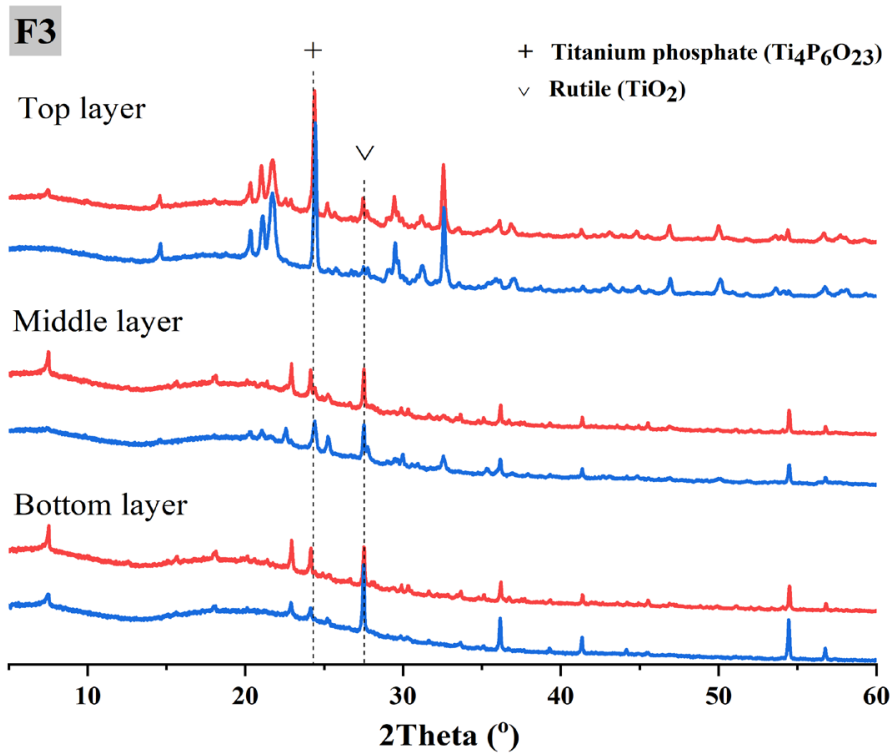

F4
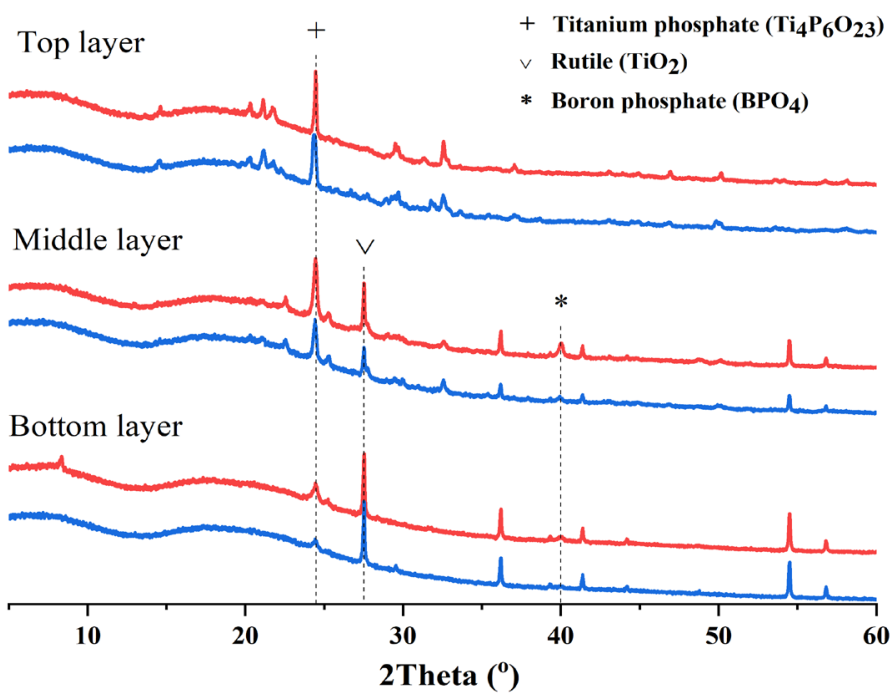

F5

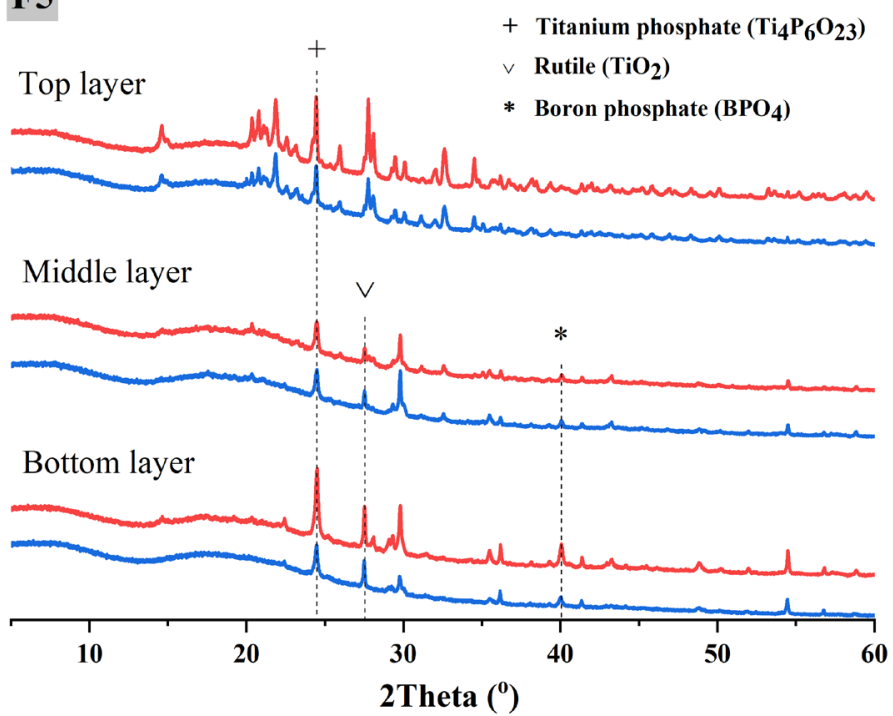

Figure $15 \mathrm{X}$-ray diffraction patterns of the three layers of the intumescent coating chars. 


\section{Conclusions}

A laboratory-scale setup, modified from a commercially available furnace, is proposed for the fast evaluation of hydrocarbon intumescent coatings in the laboratory. Taking advantage of the high heating rates of the furnace, the setup can perform fire-resistance experiments according to the standard fire test curve, UL1709. The reliability of the setup was examined by comparing its efficiency with an industrial furnace with respect to fire-resistance performance of coatings including physical appearance and chemical compositions of the chars. Temperature responses of the steel plates obtained in fire-resistance experiments showed a high accuracy and repeatability, supporting the use of the laboratory-scale furnace for investigation and screening of hydrocarbon intumescent coatings.

As a case study, five hydrocarbon intumescent coatings were selected and assessed in the laboratoryscale and industrial furnace experiments, respectively. Owing to the similar heating conditions (dwell temperature, heating rate, and heat dissipation), the two types of furnace experiments showed a high consistency in their temperature response of steel plates coated with a specific coating. The exposure times to critical temperatures, obtained in the laboratory-scale furnace, showed the same ranking of the coatings as that in the industrial furnace. An investigation of the chars formed in the experiments, showed that the laboratory- and industrial-scale furnaces can be correlated for the physical appearance (relative expansion and morphological structure) and chemical composition (crystalline phases) of the chars, although the char defects (e.g. detachments and/or cracks), due to turbulence from gas combustion and scaled-up sample size, were much more pronounced in the gas-fueled industrial furnace. Nevertheless, these good correlations suggest that the laboratory-scale furnace is a promising tool to evaluate fire-resistance performance of hydrocarbon intumescent coatings and to provide a reliable indication of the char potential for thermal insulation.

\section{Funding}

The authors disclosed receipt of the following financial support for the research, authorship, and publication of this article: This work was supported by the Hempel Foundation to CoaST (The Hempel Foundation Coatings Science and Technology Centre).

\section{Declaration of conflicting interests}

The authors declare that there is no conflict of interest.

\section{Reference}

1. Mariappan T. Recent developments of intumescent fire protection coatings for structural steel: 
A review. J Fire Sci 2016; 34: 120-163.

2. Elliott A, Temple A, Maluk C, et al. Novel Testing to Study the Performance of Intumescent Coatings under Non-Standard Heating Regimes. Fire Saf Sci 2014; 11: 652-665.

3. Anderson CE, Wauters DK. A thermodynamic heat transfer model for intumescent systems. Int J Eng Sci 1984; 22: 881-889.

4. Jimenez M, Duquesne S, Bourbigot S. High-Throughput Fire Testing for Intumescent Coatings. Ind Eng Chem Res 2006; 45: 7475-7481.

5. Purkiss JA, Li L-Y. Fire Safety Engineering Design of Structures. 3rd ed. Florida: CRC Press, 2013, p.41.

6. Yuan J. Intumescent Coating Performance on Steel Structures under Realistic Fire Conditions. $\mathrm{PhD}$ thesis, University of Manchester, UK, 2009.

7. Jimenez M, Duquesne S, Bourbigot S. Kinetic analysis of the thermal degradation of an epoxybased intumescent coating. Polym Degrad Stab 2009; 94: 404-409.

8. Maluk C, Bisby L, Terrasi G, et al. Novel Fire Testing Methodology: Why, How and What Now? Proc mini Symp Perform based Fire Saf Eng Struct as part 1st Int conferance perfomance based L life cycle Struct Eng 2012; 448-458.

9. Gillani QF, Ahmad F, Mutalib MIA, et al. Effect of Dolomite Clay on Thermal Performance and Char Morphology of Expandable Graphite Based Intumescent Fire Retardant Coatings. Procedia Eng 2016; 148: 146-150.

10. Aziz H, Ahmad F. Effects from nano-titanium oxide on the thermal resistance of an intumescent fire retardant coating for structural applications. Prog Org Coatings 2016; 101: 431-439.

11. Ullah S, Ahmad F, Shariff AM, et al. Effects of ammonium polyphosphate and boric acid on the thermal degradation of an intumescent fire retardant coating. Prog Org Coatings 2017; 109: $70-82$.

12. Wang J, Wang G. Influences of montmorillonite on fire protection, water and corrosion resistance of waterborne intumescent fire retardant coating for steel structure. Surf Coatings Technol 2014; 239: 177-184.

13. Bodzay B, Bocz K, Bárkai Z, et al. Influence of rheological additives on char formation and fire resistance of intumescent coatings. Polym Degrad Stab 2011; 96: 355-362.

14. Duquesne $\mathrm{S}$, Bachelet $\mathrm{P}$, Bellayer $\mathrm{S}$, et al. Influence of inorganic fillers on the fire protection of intumescent coatings. J Fire Sci 2013; 31: 258-275.

15. Tian N, Delichatsios MA, Zhang J, et al. A methodology and a simple engineering fire performance model for Intumescent Fire Retardant coatings. Fire Saf J 2018; 98: 120-129.

16. Zia-ul-Mustafa M, Ahmad F, Ullah S, et al. Thermal and pyrolysis analysis of minerals reinforced intumescent fire retardant coating. Prog Org Coatings 2017; 102: 201-216.

17. Gardelle B, Duquesne S, Vandereecken P, et al. Resistance to fire of curable silicone/expandable graphite based coating: Effect of the catalyst. Eur Polym J 2013; 49: 20312041.

18. Cirpici BK, Wang YC, Rogers B. Assessment of the thermal conductivity of intumescent coatings in fire. Fire Saf J 2016; 81: 74-84. 
19. Wang L, Chen B, Zhang C, et al. Experimental study on insulative properties of intumescent coating exposed to standard and nonstandard furnace curves. Fire Mater 2019; 43: 782-793.

20. Mariappan T, Agarwal A, Ray S. Influence of titanium dioxide on the thermal insulation of waterborne intumescent fire protective paints to structural steel. Prog Org Coatings 2017; 111: $67-74$.

21. Jimenez M, Bellayer S, Revel B, et al. Comprehensive Study of the Influence of Different Aging Scenarios on the Fire Protective Behavior of an Epoxy Based Intumescent Coating. Ind Eng Chem Res 2013; 52: 729-743.

22. Morys M, Illerhaus B, Sturm H, et al. Revealing the inner secrets of intumescence: Advanced standard time temperature oven (STT Mufu + )- $\mu$-computed tomography approach. Fire Mater 2017; 41: 927-939.

23. Gardelle B, Duquesne S, Vandereecken P, et al. Resistance to fire of intumescent silicone based coating: The role of organoclay. Prog Org Coatings 2013; 76: 1633-1641.

24. Gardelle B, Duquesne S, Vandereecken P, et al. Characterization of the carbonization process of expandable graphite/silicone formulations in a simulated fire. Polym Degrad Stab 2013; 98 : 1052-1063.

25. Jimenez M, Bellayer S, Naik A, et al. Topcoats versus Durability of an Intumescent Coating. Ind Eng Chem Res 2016; 55: 9625-9632.

26. Naik AD, Duquesne S, Bourbigot S. Hydrocarbon time-temperature curve under airjet perturbation: An in situ method to probe char stability and integrity in reactive fire protection coatings. J Fire Sci 2016; 34: 385-397.

27. Zeng Y, Weinell CE, Dam-Johansen K, et al. Exposure of hydrocarbon intumescent coatings to the UL1709 heating curve and furnace rheology: Effects of zinc borate on char properties. Prog Org Coatings 2019; 135: 321-330.

28. Gardelle B, Duquesne S, Rerat V, et al. Thermal degradation and fire performance of intumescent silicone-based coatings. Polym Adv Technol 2013; 24: 62-69.

29. Murat Unlu S, Tayfun U, Yildirim B, et al. Effect of boron compounds on fire protection properties of epoxy based intumescent coating. Fire Mater 2017; 41: 17-28.

30. Lucherini A, Abusamha N, Segall-Brown J, et al. Experimental study on the onset of swelling for thin intumescent coatings. J Phys Conf Ser 2018; 1107: 032017-1-032017-6.

31. Lucherini A, Maluk C. Assessing the onset of swelling for thin intumescent coatings under a range of heating conditions. Fire Saf J 2019; 106: 1-12.

32. Nørgaard KP, Dam-Johansen K, Català P, et al. Investigation of char strength and expansion properties of an intumescent coating exposed to rapid heating rates. Prog Org Coatings 2013; 76: $1851-1857$.

33. Morys M, Illerhaus B, Sturm H, et al. Size is not all that matters: Residue thickness and protection performance of intumescent coatings made from different binders. J Fire Sci 2017; 35: 284-302.

34. Chou C-S, Lin S-H, Wang C-I. Preparation and characterization of the intumescent fire retardant coating with a new flame retardant. Adv Powder Technol 2009; 20: 169-176.

35. Puri RG, Khanna AS. Intumescent coatings: A review on recent progress. J Coatings Technol 
Res 2017; 14: 1-20.

36. Kahraman HT, Gevgilili H, Pehlivan E, et al. Development of an epoxy based intumescent system comprising of nanoclays blended with appropriate formulating agents. Prog Org Coatings 2015; 78: 208-219.

37. UL 1709: 2007. Rapid Rise Fire Tests of Protection Materials for Structural Steel.

38. Zhang Y, Wang YC, Bailey CG, et al. Global modelling of fire protection performance of intumescent coating under different cone calorimeter heating conditions. Fire Saf J 2012; 50: $51-62$.

39. Nørgaard KP, Dam-Johansen K, Català P, et al. Laboratory and gas-fired furnace performance tests of epoxy primers for intumescent coatings. Prog Org Coatings 2014; 77: 1577-1584.

40. Nørgaard KP, Dam-Johansen K, Kiil S, et al. Engineering model for intumescent coating behavior in a pilot-scale gas-fired furnace. AIChE $J$ 2016; 62: 3947-3962.

41. Griffin GJ, Bicknell AD, Brown TJ. Studies on the Effect of Atmospheric Oxygen Content on the Thermal Resistance of Intumescent, Fire-Retardant Coatings. J Fire Sci 2005; 23: 303-328.

42. Morys M, Illerhaus B, Sturm H, et al. Variation of Intumescent Coatings Revealing Different Modes of Action for Good Protection Performance. Fire Technol 2017; 53: 1569-1587.

43. Fateh T, Guillaume E, Joseph P. An experimental study of the thermal performance of a novel intumescent fire protection coating. Fire Saf J 2017; 92: 132-141. 